\title{
Epidemiology of Congenital Clefts of the Lip and Palate
}

\author{
JOHN C. GREENE, D.M.D., M.P.H.
}

M AN has been plagued through the ages by the threat of producing deformed offspring. Recognition of birth defects appears in the medical writings of Celsus, who lived nearly 2,000 years ago. He discussed "the operation necessary in a want of substance in the ears, lips, and nose."

Until recent years, the birth of a child with a cleft of the lip or palate was surrounded by superstition and mystery. All congenital malformations were commonly ascribed to a multitude of natural and supernatural prenatal influences. Many medical scientists, hampered by their inability to make direct observations of human fetal development within the uterus, ascribed malformations to defective inheritance and adopted a fatalistic attitude toward them (1).

Before 1940, attempts to learn more about cleft lip and palate focused primarily on studies of incidence in special populations and among families of probands. Following the announcement in 1940 that congenital malformations had been produced in animals whose mothers were reared on deficient diets, a new era of investigation began (2). The search for environmental agents in the etiology of cleft lip and palate was undertaken in earnest.

Though the scientific literature which has resulted from this search is voluminous, scientists must become familiar with it if they are to acquire even a superficial understanding of

Dr. Greene is chief, Epidemiology Branch, National Dental Health Center, Division of Dental Public Health and Resources, Public Health Service, San Francisco, Calif. the many forces which may be at work in producing cleft lip and cleft palate.

The following review of the literature was undertaken as part of the preparation for conducting investigations in the epidemiology of cleft lip and palate. The terms "cleft lip" and "cleft palate" refer to material defects that are present at birth in the upper lip, alveolus, or hard or soft palate. Possible microforms, such as missing lateral incisors, high vault, and bifid uvula, are not knowingly included in the data except where specified. The following abbreviations are used: "CL" for isolated cleft lip, "CP" for isolated cleft palate, and "CL(P)" for cleft lip with or without cleft palate. Clefts unspecified as to type or location are referred to simply as clefts. The material is presented under three headings: pathogenesis, incidence, and etiology.

\section{PATHOGENESIS}

One theory of pathogenesis holds that, in humans, failure of the frontonasal process to fuse with the two lateral maxillary processes during the fifth to eighth week of gestation results in a cleft of the upper lip. It also proposes that beginning about the ninth week of pregnancy the two palatine processes either fuse to form the palate or fail to fuse and form a palatal cleft (3).

Another theory, sometimes called the theory of mesodermal penetration, suggests that the normal lip is formed by an ectodermal hood which is invaded and supported by mesoderm arising from three islands within the hood, not by fusion of processes. Failure of the meso- 
derm to infiltrate the hood permits the delicate ectodermal membrane to thin, rupture, and form a cleft of the lip. The proponents of both theories of cleft lip pathogenesis are essentially in agreement on cleft palate formation $(3-5)$.

The mesodermal penetration theory is particularly interesting because it provides the basis for hypothesizing that the development of the normal lip and palate differ both in mechanism and in time and that agents which affect one would not necessarily affect the other. In other words, clefts of the lip and palate may differ etiologically.

\section{INCIDENCE}

The number of cases of cleft lip and palate reported to occur in the United States or any other country is, at best, a gross estimate based on isolated bits of information gleaned from vital statistics, crippled children's registers, hospital records, and other sources. Comprehensive data are not available on whether clefts are occurring more frequently in this decade than in the last or whether cases are occurring more frequently in some geographic areas or in some racial groups than others. Reports from a number of special studies, however, provide some basis for speculating about cleft lip and palate incidence in the United States and other countries and for developing hypotheses concerning factors which may be associated with the occurrence of cases.

Figures compiled by Hixon (6), combined with more recent data $(y-12)$, clearly show the wide variation in estimates of cleft lip or cleft palate incidence (table 1). It could be concluded from the table that cleft cases are occurring more frequently today than formerly. For example, in 1908 in London, England, the ratio of cases to live births was reported to be $1: 1,742$, while in 1950 , the ratio for Birming-

Table 1. Estimates of the frequency of cleft lip and cleft palate

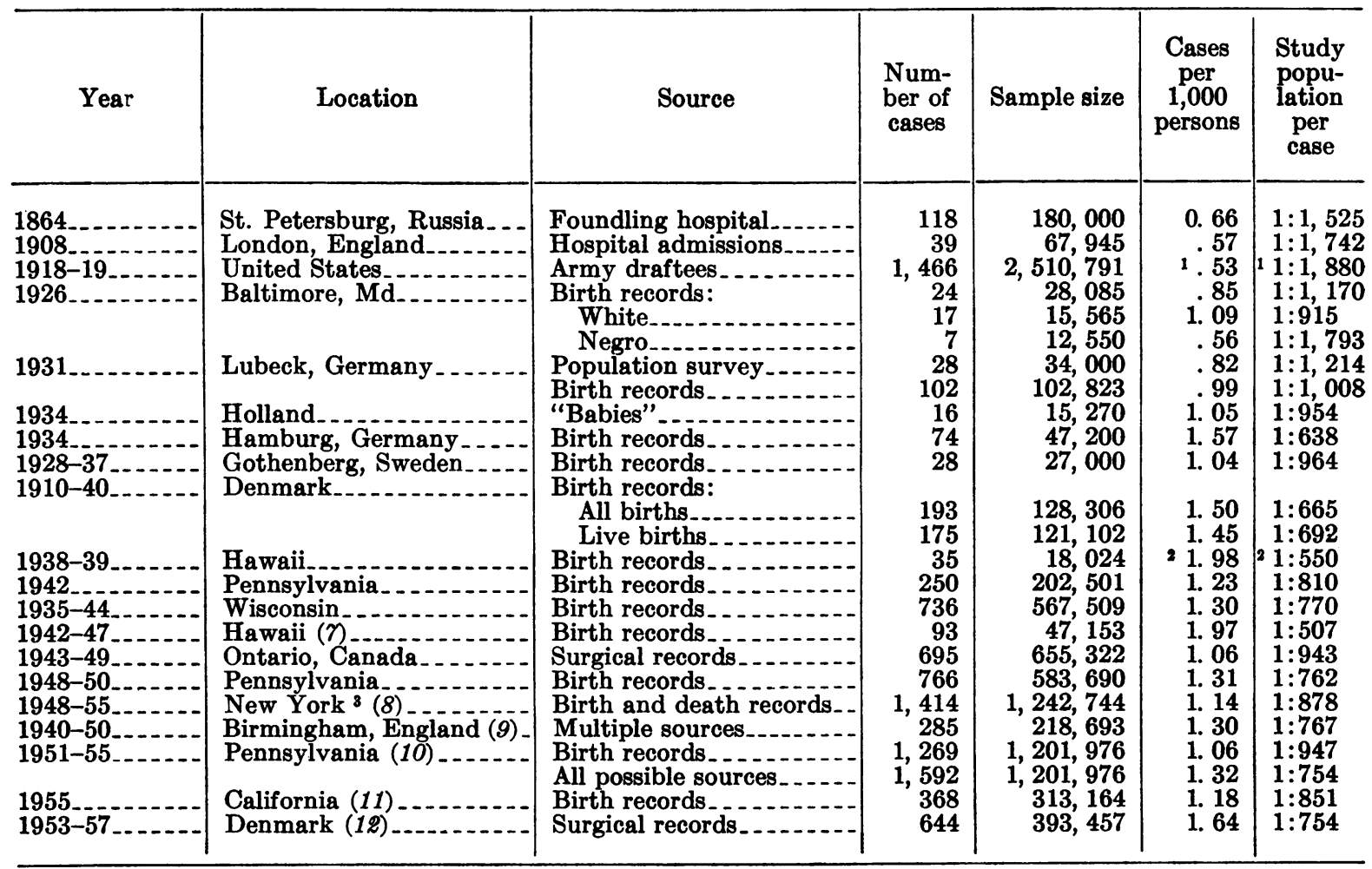

1 According to data given, should be 0.58 cases per 1,000 and $1: 1,713$.

2 According to data given, should be 1.94 cases per 1,000 and 1:515.

3 Exclusive of New York City.

SourcEs: Reference 6, except where another reference is cited after location of study. 
ham, England, was reported to be 1:767. Drawing such a conclusion, however, does not seem warranted. Possible sources of variation in the data which may explain the apparent increase are case sources, completeness of casefinding, criteria for selecting cases, sample size, and decreased perinatal mortality. Because of this lack of comparability, the data presented should be viewed primarily as a range of values for cleft lip and palate incidence rather than an indication of any real increase in the case rate.

Fogh-Andersen's recent report (12) on cleft lip and palate patients who underwent surgery in Denmark between 1938 and 1957 shows a steady increase from 1.31 to 1.64 cases per 1,000 live births. $\mathrm{He}$ considered whether these data reflected an actual or an apparent increase in the incidence of cleft lip and palate and implied that at least part of the increase was real. The apparent increase in case incidence may have resulted from an increasing proportion of all persons with clefts who obtained surgical repair. On the other hand, assuming a genetic basis for some clefts, part of the real increase in incidence may be explained by the steadily improving plastic surgery and habilitation methods which enable more persons with clefts to marry.

An accurate ratio of cleft lip and palate births to all live births is not available for the United States. Data shown in table 1 from selected studies conducted in the United States since 1935 provide an estimate of $1.3 \mathrm{cleft}$ births for every 1,000 live births. Using this very gross estimate together with a birth rate of 24.1 per 1,000 population per year (13) and the 1960 population figure of 179.3 million (1.4), it can be conservatively estimated that nearly 6,000 new cases of lip and palatal clefts occur each year in the United States.

\section{Sex of Child and Type of Cleft}

A few of the larger studies provide information on the distribution of cases by sex and by type of cleft deformity $(6,9,12,15-19$, table 2$)$. The sources of information and methods of data collection differ in these studies, but, with few exceptions, they agree on several points: cleft lip and cleft palate occur more frequently together than separately; clefts of the lip with or without associated clefts of the palate are more common in the male than in the female (65:35) ; CP cases are more common in the female $(60: 40)$; and when all types of clefts of the lip and palate are considered together, males are more frequently affected $(58: 42)$. This peculiar sex distribution of the types of clefts was described by Fogh-Andersen in 1942(15).

The marked sex difference in prevalence between cases with $\mathrm{CL}(\mathrm{P})$ and those with $\mathrm{CP}$ led Fogh-Andersen to compare these cleft types by family history (15). The family patterns of prevalence of CL cases and cases with clefts of the lip and palate appeared very similar with respect to the lack of isolated cleft palate cases among close relatives. The two conditions,

\section{Table 2. Distribution of cleft lip, cleft lip and cleft palate, and cleft palate cases by sex and by percent of total cases as reported in selected sfudies}

\begin{tabular}{|c|c|c|c|c|}
\hline \multirow{2}{*}{$\underset{\text { location }}{\text { Malformation and study }}$} & \multirow{2}{*}{$\begin{array}{c}\text { Num- } \\
\text { ber } \\
\text { of } \\
\text { cases }\end{array}$} & \multirow{2}{*}{$\begin{array}{c}\text { Per- } \\
\text { cent } \\
\text { of } \\
\text { total } \\
\text { cases } \\
\text { in } \\
\text { study }\end{array}$} & \multicolumn{2}{|c|}{ Males } \\
\hline & & & $\underset{\text { ber }}{\text { Num- }}$ & $\begin{array}{l}\text { Per- } \\
\text { cent }\end{array}$ \\
\hline 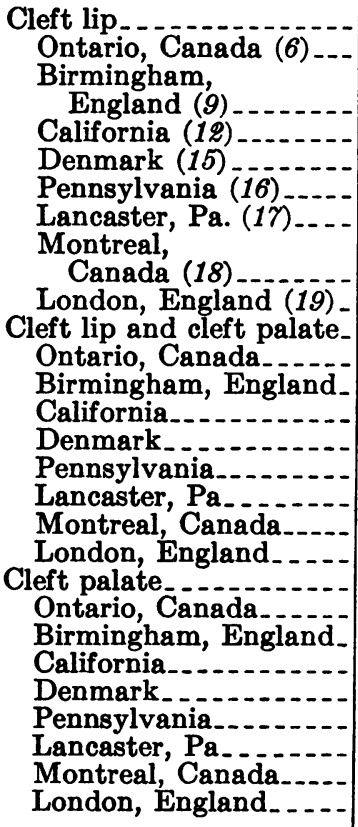 & \begin{tabular}{|r}
873 \\
195 \\
66 \\
102 \\
138 \\
229 \\
36 \\
\\
14 \\
93 \\
1,893 \\
316 \\
105 \\
155 \\
360 \\
356 \\
393 \\
56 \\
152 \\
1,141 \\
123 \\
114 \\
111 \\
127 \\
181 \\
242 \\
32 \\
211
\end{tabular} & $\begin{array}{r}22.3 \\
30.8 \\
23.2 \\
27.8 \\
22.1 \\
29.9 \\
5.4 \\
13.7 \\
20.4 \\
48.5 \\
49.8 \\
36.8 \\
42.1 \\
57.6 \\
46.5 \\
58.6 \\
54.9 \\
33.3 \\
29.2 \\
19.4 \\
40.0 \\
30.2 \\
20.3 \\
23.6 \\
36.1 \\
31.4 \\
46.3\end{array}$ & $\begin{array}{r}6 \\
61 \\
1,243 \\
199 \\
62 \\
90 \\
257 \\
228 \\
267 \\
37 \\
103 \\
465 \\
55 \\
47 \\
40 \\
43 \\
69 \\
103 \\
14 \\
94\end{array}$ & $\begin{array}{l}60.6 \\
59.8 \\
65.2 \\
69.9 \\
52.8 \\
42.9 \\
65.6 \\
65.7 \\
63.0 \\
59.0 \\
58.1 \\
71.4 \\
64.0 \\
67.9 \\
66.1 \\
67.8 \\
40.8 \\
44.7 \\
41.2 \\
44.0 \\
33.9 \\
38.1 \\
42.6 \\
43.8 \\
44.5\end{array}$ \\
\hline Total & 3,907 & 100.0 & 2,272 & 58. 2 \\
\hline
\end{tabular}

Sources: References 6, 9, 12, 15-19. 
$\mathrm{CL}(\mathrm{P})$ and $\mathrm{CP}$, seem to be generally consistent in the way they occur among relatives (table 3 ). For example, among relatives of $\mathrm{CL}(\mathrm{P})$ cases, the observed number of $\mathrm{CL}(\mathrm{P})$ cases is significantly greater than expected, while the observed number of CP cases does not differ from the expected number. Among relatives of CP cases, the observed number of cases of CP is significantly greater than expected, and the observed number of $\mathrm{CL}(\mathrm{P})$ cases is not significantly different from the expected number. From these data, Fogh-Andersen's interpretation that hereditarily $\mathrm{CL}(\mathrm{P})$ and $\mathrm{CP}$ are two mutually independent malformations seems justified. The influence of hereditary factors on $\mathrm{CL}(\mathrm{P})$ and $\mathrm{CP}$ is discussed more fully in the section on etiology; however, the point to be emphasized here is that, whenever possible, the two conditions - cleft lip and cleft palateshould be studied as separate entities.

The combined data from all of the studies listed in table 2 show that 22 percent of the patients had cleft lip, 49 percent had cleft lip and cleft palate, and 29 percent had cleft palate. However, this proportional distribution was not found consistently. The Lancaster and Montreal studies $\left(1^{n y}, 18\right)$ reported only a small percentage of CL cases. Because those included in these studies were patients who came to a clinic for surgical repair, it is unlikely that the sample was representative of clefts of all types and severity. Probably a high percentage of

\section{Table 3. Observed and expecied number of cases of isolated cleft palate (CP) and cleft lip with or without associated cleft palate (CL(P)) among relatives of index cases in Denmark}

\begin{tabular}{|c|c|c|c|c|c|}
\hline \multirow{2}{*}{$\begin{array}{c}\text { Type of } \\
\text { cleft in } \\
\text { index case }\end{array}$} & \multirow{2}{*}{$\begin{array}{c}\text { Number } \\
\text { of rela- } \\
\text { tives }\end{array}$} & \multicolumn{2}{|c|}{$\begin{array}{l}\text { Observed clefts } \\
\text { among relatives }\end{array}$} & \multicolumn{2}{|c|}{$\begin{array}{l}\text { Expected clefts } \\
\text { among relatives }\end{array}$} \\
\hline & & Type & $\underset{\text { ber }}{\text { Num- }}$ & Type & $\underset{\text { ber }}{\text { Num- }}$ \\
\hline $\begin{array}{l}\mathrm{CL}(\mathrm{P}) \\
\text { (498 cases) }\end{array}$ & 17,327 & $\left\{\begin{array}{l}\mathrm{CL}(\mathrm{P}) \\
\mathrm{CP}\end{array}\right.$ & $\begin{array}{r}148 \\
7\end{array}$ & $\begin{array}{l}\mathrm{CL}(\mathrm{P}) \\
\mathrm{CP}\end{array}$ & $\begin{array}{r}19.13 \\
6.95\end{array}$ \\
\hline $\begin{array}{l}\text { CP } \\
\text { (205 cases) }\end{array}$ & 7,562 & $\left\{\begin{array}{l}\mathrm{CL}(\mathrm{P}) \\
\mathrm{CP}\end{array}\right.$ & $\begin{array}{r}4 \\
55\end{array}$ & $\begin{array}{l}\mathrm{CL}(\mathrm{P}) \\
\mathrm{CP}\end{array}$ & $\begin{array}{l}\text { 8. } 32 \\
\text { 3. } 04\end{array}$ \\
\hline
\end{tabular}

1 Based on observed rates in Denmark population at large: $1.1 \mathrm{CL}(\mathrm{P})$ cases and $0.4 \mathrm{CP}$ case per 1,000 population.

SouRce: Reference 15 , p. 158 , modified to show expected rates. cases which were difficult to repair and a low percentage of those easier to repair, such as simple clefts of the lip, were referred to these clinics. The two English studies $(9,19)$ reported an unusually high proportion of isolated cleft palate cases. Whether the difference in methods of case selection was responsible for this difference in distribution of cases is not known.

Many investigators have noted the preponderance of clefts of the left side of the lip $(15,19$ 22). From 61 to 77.9 percent of the unilatera] clefts with or without associated cleft palate are reported to occur on the left side. No satisfactory explanation for this predilection has appeared in the literature.

\section{Parental Age and Birth Order}

A number of studies have found no apparent relationship between maternal age and frequency of clefts $(15,23-25)$. In a study conducted in Detroit, the distributions of 282 babies born with clefts and 7,927 normal births were compared by age of father and mother (23). No relationship between parental age and frequency of cleft formation was noted nor did attack rates vary significantly with birth order. Peer and associates, in another report (24), concluded that there was no relationship between age of mother or father and incidence of clefts; however, they presented no supporting data.

Investigators in the Pacific Northwest (25) concluded that mothers between 19 and 24 years of age gave birth to more babies with clefts than did mothers in other age groups. Because the data were based on counts of cases rather than on age-specific attack rates, their significance is questionable.

In one study of the relationship between parental age and clefts, type of cleft was considered (15), but no positive relationship was demonstrated, possibly because of the statistical techniques employed. The mean age of mothers of children with clefts was compared with the mean age of all Danish women who gave birth to a child in a single year. A similar procedure was followed when considering age of father. Though the procedures followed are appropriate enough, data grouped in this way can mask existing associations un- 
less these are very pronounced. In the same study, no association was found between the occurrence of cleft cases and birth order.

In a study based on case rates by maternal age in Birmingham, England (9), a statistically significant association was found between $\mathrm{CL}(\mathrm{P})$ and maternal age but not between CP and maternal age. No association was noted between $\mathrm{CL}(\mathrm{P})$ or $\mathrm{CP}$ and birth order.

Data from the Lancaster clinic on patients reporting for treatment (17) show an apparent tendency for children with clefts to be born to older mothers. The ages of mothers at the time they gave birth to children with cleft deformities were compared with the ages of the same mothers at the time their other children were born. Using this analytical procedure, if the birth of a child with a cleft discouraged the parents from having additional children, it would appear that the normal children were born when the mothers were younger and the defective children were born when the mothers were older. Collectively, it would appear that an association exists between maternal age and the birth of babies with clefts.

In the same study, Mazaheri reported on clefts among first-born children. Twenty-five percent, or 19, of the first-born children with clefts were born to mothers under 20 years old; 49 percent, or 32 , were born to mothers more than 30 years old.

In the families of children with clefts, Mazaheri found a statistically significant positive relationship between clefts and birth order. It should be reiterated, however, that this relationship is open to question because the birth of a defective child may have discouraged further pregnancies. In addition, the question of the representativeness of the cases available limits the interpretation of the findings of any study based on chance reporting of patients for treatment.

Studies in Wisconsin (20) and California (11) have shown a disproportionately large number of babies with clefts born to mothers more than 35 years of age. The father's age also was shown to be related to the occurrence of clefts in the study by Fraser and Calnan (19). They demonstrated a positive relationship between older paternal age and the incidence of cleft lip and cleft palate combined.
If an association does exist between maternal age and the incidence of clefts, the association is not very pronounced. The literature contains a number of studies which deny the association and number which support it.

\section{Race}

The few studies which have reported on differences in the frequency of clefts among races agree that clefts are seen much less frequently among Negroes than among whites. Davis (26) reported that only 7 cleft cases were observed among 12,520 births of Negro children (0.55 per 1,000 live births) at Johns Hopkins Hospital. During the same period, there were 17 cases among 15,565 births of white children (1.06 per 1,000 live births).

Lutz and Moor (27) reported on 303 cleft cases among births in a hospital. By race, the cleft case rates per 1,000 live births were: Caucasian, 1.00; Mexican, 1.25; and Negro, 0.71 . Loretz and associates (11) found that in California in 1955, 6.9 percent of all births were to Negroes, but only 3.5 percent of the children born with clefts were Negroes. In Pennsylvania, Grace (28) found that 5.6 percent of the children born in 1942 were Negroes, but only 3.6 percent of those born with clefts were Negroes.

In Hawaii, Krantz and Henderson (y) studied the frequency of cleft cases in relation to maternal ancestry. This study demonstrated lower rates among offspring of mothers of "unmixed" ancestry than among children born to mothers of "blended" ancestry. They found that children of Filipino mothers who are a blend of black, brown, yellow, and white races have an attack rate significantly higher (3.50 per 1,000 live births) than children born to Caucasian mothers ( 0.5 per 1,000 live births). However, these rates are based on very few cases.

Though these studies of racial factors constitute limited observations made on selected populations, they strongly suggest that there are differences in attack rates among the races. 'The rates are lower for Negroes than for whites, and the rates are higher for "blended" races than for whites. These differences, of course, may be due to concomitant environmental influences rather than racial factors. 


\section{Geography}

Very little information is available on the geographic distribution of cases of congenital clefts in the United States. The only data for the nation as a whole were derived from examinations of World War I draftees (29), and even these were based on place of residence at the time of examination, not necessarily on place of birth. Only "significant blemishes" were recorded. Though the data are interesting, they have almost no statistical value.

A study in Hawaii by Henderson (30) reported 1.98 cleft cases per 1,000 live births. This attack rate, the highest reported in the United States, probably is influenced considerably by Hawaii's mandatory reporting system which has been in effect since 1938. Krantz and Henderson attributed a large portion of the excess of clefts in Hawaii to the high case rate among the Filipinos ( $(y)$.

Many other States have reported rates also, but a lack of comparability prevents the drawing of meaningful conclusions. The fact that these rates vary markedly is nevertheless intriguing.

\section{Season of Birth}

Lutz and Moor found that among 303 children with clefts born in the Los Angeles County General Hospital between July 1936 and Decembar 1951, more children with clefts were born during June, July, and August than in any other 3-month period (27). The seasonal distribution of normal births was not described. Stevenson and his co-workers (1) reviewed the obstetrical records of all mothers who gave birth to malformed infants in the Boston Lying-In Hospital between 1930 and 1941. During that time, 677 malformed children were born. Of these, 34 had clefts. A significantly large number of the infants with multiple defects were conceived in the first and fourth quarters of the year. The cleft cases were too few in number to be analyzed separately.

No unusual seasonal variations were found in the 456 cleft cases reported by Fraser and Calnan (19).

The studies published to date do not rule out the possibility of seasonal differences in the incidence of cleft cases.

\section{Associated Congenital Abnormalities}

MacMahon and McKeown (9) reported that 15.8 percent of the cleft cases they studied were associated with other congenital malformations. Other malformations were found in 9.1 percent of the CL cases, 14.9 percent of the CP cases, and 21 percent of those with both cleft lip and cleft palate. Fogh-Andersen (15) found other severe malformations in 10 percent or more of the cleft cases he observed. Beder and associates (25) reported associated anomalies in 14.5 percent of the cases they studied in the Pacific northwest. According to Fraser and Calnan (19), other abnormalities were found to be more frequently associated with CP than with cases having lip involvement.

Among the many congenital abnormalities found to coexist with facial clefts are syndactylism; supernumerary fingers, toes, and teeth; malformed ears; spina bifida; clubfoot; and congenital heart disease (31). In all probability, the published figures of 9 to 21 percent represent the minimum frequency with which clefts are actually associated with other congenital malformations inasmuch as many developmental defects of the newborn are difficult to detect.

\section{ETIOLOGY}

The apparent differences in the frequency of occurrence of cleft lip and cleft palate cases according to sex, maternal age, birth order, race, geography, seasons of the year, and combinations with other malformations serve only as clues which may help lead to the discovery of causes of cleft lip and palate. The literature goes far beyond the presentation of such clues, however. It is replete with epidemiologic data which are used in attempts to describe what may be causes of facial clefts. Heredity, nutrition, stress, infectious diseases, and X-radiation have been indicted as possible etiological factors.

\section{Heredity}

The role of heredity in the etiology of cleft lip and cleft palate has been investigated extensively, particularly along three axes: studies of clefts in family groups, clefts in identical and heterozygous twins, and modes of inheritance. 
Family studies. In 1942, Fogh-Andersen published a detailed description of 703 cleft patients and their pedigrees (15). The study group included 625 patients admitted for surgery over a 7-year period and 78 patients with CP who were attending a speech institute. Because it is usually the people with the more severe conditions who seek surgery and speech therapy, the caseload probably did not include a good representation of patients with minor defects. On the other hand, some of those who were most severely affected probably died before admittance to surgery; this would compensate to some unknown extent for any adverse selection.

For comparative purposes, Fogh-Andersen calculated the frequency of cleft cases in the total population by using birth and treatment records from six hospitals in Denmark. The author points out at least three potential sources of error in these figures: the frequency figure is controlled by the number of cases admitted for surgery each year; some cases among the newborn may have escaped registration; and the majority of the birth records came from a hospital where most of the births are out of wedlock. Whether any relationship exists between illegitimacy and cleft lip or palate is not known.

Upon comparing the frequency of clefts among relatives of the patients included in the index group and among the general population, Fogh-Andersen found the following differences to be statistically significant at the 0.01 level: (a) the difference between frequency of occurrence of $\mathrm{CL}(\mathrm{P})$ in the total population and frequency among siblings, parents, and parents' siblings of CL(P) patients, and (b) the frequency of occurrence of CP in the total population and among siblings of CP patients.

$\mathrm{He}$ determined that the difference between the mean frequency of occurrence of clefts among relatives other than siblings of the index cases and the mean frequency of occurrence among the total population was $0.45 \pm 0.06$ percent for the $\mathrm{CL}(\mathrm{P})$ group and $0.57 \pm 0.10$ percent for the CP group. In relation to these figures, the author stated, "Thus it has been proved that a hereditary disposition is a concurrent cause both of cleft lip and palate and isolated cleft palate." These observations demonstrate aggregations of cases in these families, but they do not prove that hereditary factors are involved in the development of clefts nor do they rule out the influences of nonhereditary factors. Nevertheless, the author has presented evidence which strongly suggests that hereditary factors are important in the etiology of facial clefts.

Schwartz (32) studied the aggregation of cleft cases among relatives of CP cases at the Institute of Logopedics in Wichita, Kans., an institute for study and treatment of speech defects. The family histories of 227 patients with CP were compared with family histories of 100 controls drawn from noncleft patients listed in the files of the same institute. Information was obtained for about 949 relatives. Thirtyfive cleft patients (15.4 percent) and two of the controls ( 2 percent) reported that other members of their families had clefts. Because this was a select group of patients, the data from this study probably are not generally applicable.

Stiegler and Berry (31), in a study of family histories, reported that 26 percent of 164 cleft patients knew of cleft cases among their relatives. Peer and associates (24), in a study based on a 40 percent return of questionnaires sent to 1,000 mothers of children with repaired clefts, found that 23 percent of the children had positive family histories. Positive family history was reported in 18.9 percent of CL cases, 24.9 percent of cleft lip and palate cases, and 25.6 percent of CP cases. Although interesting, data derived in this manner have severe limitations. For example, the patients undergoing surgery probably are not representative of all cleft patients; the 40 percent who responded to the questionnaires may differ from those who failed to respond; and, finally, the accuracy of data derived from questionnaires is unknown.

In 1928, Davis reported that 57 percent of 425 consecutive cleft patients who came to him for surgery had a positive family history (21). However, the criteria for a positive family history included not only cases of clefts of the lip, face, and palate but also microforms such as congenital absence of superior lateral incisors or supernumerary superior lateral incisors. In 1935, again including microforms, Davis re- 
ported that 54 percent of 944 patients with congenital deformities of the upper lip or palate gave positive family histories (33).

Fraser and Baxter (18), investigating the distribution of clefts among families of 70 CL(P) patients in Montreal, Canada, found that 9 out of 140 siblings ( 6.4 percent) of patients in the index group had clefts. FoghAndersen (15) reported a 4.9 percent prevalence among siblings of a group of CL(P) patients. In the Montreal study, among 101 siblings of 32 patients with CP, 3 , or 3.0 percent, had clefts. Fogh-Andersen reported 2.5 percent of the siblings of his CP patients had clefts.

Using their own data and other data from the literature, Fraser and Baxter (18) arrived at rates of risk which have been used in genetic counseling. They state that when either a parent or a sibling has a facial cleft, the unborn child has approximately a 5 percent chance of having a similar malformation. When both a parent and a sibling are affected, the risk increases to about 15 percent.

Twin studies. On the assumption that the more frequent simultaneous occurrence (concordance) of a congenital condition among monozygotic twins than among dizygotic twins means that genetic factors are at least partially involved in the development of the condition, Fogh-Andersen (15) surveyed published case histories of 68 pairs of twins. To this information, he added data on 28 pairs of twins he personally had studied. $\mathrm{He}$ found that the difference in the percentage frequency of simultaneous occurrence of $\mathrm{CL}(\mathrm{P})$ in monozygotic and the dizygotic twins was statistically significant, but the difference was not significant for the CP group.

Metrakos and co-workers (34) added 12 twin pairs to Fogh-Andersen's report, but the relationship between the monozygotic and dizygotic pairs remained essentially unchanged. Metrakos and Fogh-Andersen concluded from these studies that heredity plays an important role in the etiology of CL(P) and probably a lesser role in the etiology of CP. This conclusion appears to be justified provided the initial assumption regarding concordance and discordance is correct and that the cases selected from the literature are representative of all twins with clefts. However, although the authors did not mention this point, the majority of the monozygotic twins reported were discordant for the condition, suggesting that nongenetic factors also play a major role in determining whether or not clefts of the lip and palate develop.

Douglas, in a review of 30 monozygotic and 70 dizygotic twins (35), none of whom were included in the two previous reviews, did not separate the CP cases from cases with lip involvement. Nine (30 percent) of the monozygotic twins were concordant compared with 5.4 percent among the dizygotic twins. This writer also emphasized the role of genetic factors in cleft formation.

The available data on the concordance of monozygotic and dizygotic twins, at least one of whom has a facial cleft, strongly indicatedespite the small numbers in the studies and the difficulties in determining zygosity-that genetic factors play a significant role in the etiology of clefts of the lip and palate. At the same time, it is quite apparent that there are other forces which impede or aid these genetic influences or independently produce phenocopies.

Mode of inheritance. It is not within the scope of this report to present a comprehensive review of all of the complicated hypotheses that have been published regarding the mechanism of inheritance of clefts of the lip and palate. The exact way in which clefts are inherited is not known. That the mechanism is not well understood, even though it occurs in experimental animals, is indicative of its complex nature. From the many writers on this subject have come a variety of possible, but yet unproved, explanations for this genetic enigma. Fogh-Andersen suggested (15), though not all authors agree $(36,37)$, that $\mathrm{CL}(\mathrm{P})$ and $\mathrm{CP}$ are two genetically independent malformations and that, in the case of $\mathrm{CL}(\mathrm{P})$, the responsible gene generally is recessive, but under favorable conditions the defect is manifested also in heterozygotes. He also stated that $\mathrm{CP}$ is genetically determined in only a small number of cases and that the manner of inheritance is that of simple dominance with low penetrance.

Warkany (38) expressed the idea that the genetic factors occur both as dominant and re- 
cessive and that the anomaly may skip a generation because of variable expressivity or reduced penetrance.

Mather and Philip (39), using the data of the geneticists Sanders and Schroeder, came to the conclusion that more than one or two genes are factors in producing cleft lip and palate, that there is at least one autosomal and one partially sex-linked gene, and that they probably are recessive.

\section{Environment}

Nutrition. In a series of laboratory studies on maternal nutrition (2, 40-43), Warkany and co-workers were able to demonstrate that cleft palate could be produced among the offspring of pregnant rats fed on diets deficient in riboflavin. By reinserting riboflavin in the diet, they were able to prevent the CP lesions. Sows fed on diets deficient in vitamin A have farrowed offspring with CL and CP (44). Following these earlier works, there have been reports of other ways of nutritionally maltreating pregnant animals to produce offspring with clefts. These include hypervitaminosis A (45) and deficiencies in folic acid (46), pantothenic acid (47), vitamin $\mathrm{E}(48)$, and nicotinamide $(49)$.

Determining the extent to which these laboratory findings apply to human beings is difficult. Warkany reported (41) that nutritional deficiencies of the fetus during sensitive stages of development can result not only from dietary deficiencies of the mother but also from maternal and placental disease too mild to cause symptoms in the mother.

Steigler and Berry (31) held that nutrition and prematurity are related in humans. They stated further that, because prematurity and clefts are related, nutrition and cleft formation should be related. These investigators contended that their study "gives support to the hypothesis of a relationship among defective nutrition, prematurity, spontaneous abortion, stillbirth, and cleft palate."

Douglas (50) suggested that vomiting during pregnancy causes depletion of certain essential elements during critical stages of pregnancy. In a study by McGanity and co-workers (51), fewer than 15 percent of the pregnant women came under the care of an obstetrician during the first trimester and thus received dietary supplements when they were most needed.

Peer and associates (24) attempted to learn whether mothers of children with clefts had taken vitamins during their ill-fated pregnancies. Of 306 mothers of children with clefts in families with negative histories, 165 reported that they had not taken vitamins during their pregnancy. Another 110 reported taking them late in the pregnancy or irregularly. Since these data were obtained by mailed questionnaires and were not compared with a control group, the findings are of doubtful significance.

One investigator (52) reported he was giving supplemental vitamins to mothers of children with clefts during the first trimester of subsequent pregnancies. The assumption, based on other studies, is that once a mother has given birth to one cleft child, there is a 5 percent chance of her having another deformed child. For this study, he selected 196 mothers of children with clefts. Eighty-seven of the 196 mothers subsequently had pregnancies. Of the 87,48 received no vitamin therapy. In the untreated group, there were 78 subsequent pregnancies, and 4 (5.1 percent) of the babies had cleft deformities. Among the 39 mothers receiving vitamin therapy during the first trimester, there were 59 subsequent pregnancies and no clefts. Even though the study was small and the published report omitted important details of the study design such as a description of the study and control groups, the study did provide some informative data. A similar study on a larger scale is being conducted in Tennessee (50).

Langman recently reported on interesting work on the influence of teratogenic agents on serum proteins (53). He found that a number of environmental teratogenic factors which caused congenital malformations in animals were accompanied by a disturbance in maternal serum proteins. He studied protein metabolism in pregnant women and found that, in cases of disturbed protein metabolism, the risk of abnormally ending a pregnancy was increased. This indicates that clefts may result from some unknown factor which interferes with the metabolic processes in the mother; the factor may possibly be related either to the mother's dietary intake or to a genetic factor. 
Stress. In laboratory experiments CP has been induced in rabbits, mice, and rats by injecting cortisone into pregnant females at a critical stage of gestation $(54-56)$. Some animal strains are known to have occasional spontaneous cleft lip with associated cleft palate, but CP is rarely observed except when experimentally produced. The interaction of genetic and environmental factors is said to be demonstrated by strain variation in response to standard doses of cortisone $\left(56^{2}\right)$. The literature contains at least two case reports $(56-58)$ on human mothers who received massive doses of cortisone during the 6th to 12 th week of pregnancy and gave birth to babies with CP. These women were being treated for existing pathology (idiopathic steatorrhea and disseminated lupus erythematosis). Other investigators have pointed out that pregnant women have been treated with cortisone without ill effects on the embryo (59).

The production of CP in laboratory animals by injection of cortisone led to the study of offspring of human mothers subjected to stress during the first trimester of pregnancy. In Peer's questionnaire study (24), 18 of 306 mothers of children with clefts reported being under severe emotional stress during the first 2 to 5 months of their pregnancy. Similar information about normal pregnancies was not presented by the authors. In another study, Strean and Peer (60), using mailed questionnaires, obtained information on the medical histories of 228 mothers of children with clefts. They reported 68 percent of the mothers underwent emotional disturbance during the first trimester of the pregnancy which produced the deformed child. Only 15 percent of the same mothers stated they suffered from similar stress during other pregnancies which produced normal offspring. As stated before, data obtained retrospectively by questionnaire are difficult to interpret since their accuracy and completeness are unknown.

Infectious diseases. Gregg's (61) observations of an unusual frequency of congenital cataracts among children conceived during a year in which rubella was epidemic in Australia resulted in numerous investigations of the relationship between maternal rubella and congenital malformations (62-76). Early enthusi- astic investigators estimated that nearly 100 percent of the women contracting rubella during the first 2 months of pregnancy would give birth to a child with congenital defects $(\%)$. However, these investigations started with cases of congenital malformations and worked retrospectively, and gave insufficient consideration to normal babies born to mothers with rubella. From later studies have come estimates that 12 to 25 percent of mothers who contract rubella in the first trimester will give birth to a congenitally malformed child $(64,71,73,76)$.

Cases of cleft lip or palate are not common among the malformations attributed to maternal rubella. In reviewing the literature, only eight cases of CP and three cases of cleft lip and palate were found among the congenital malformations ascribed to maternal rubella $(61$, 62, 67, 7\%-76). Usually CP cases represent only about one-fourth of the total in an unselected collection of cleft cases. The three cases of cleft lip and palate occurred in one study of 19 cases of rubella in the first trimester of pregnancy (75). A prospective study in Great Britain ( 76 ) found no cleft cases among births following pregnancies complicated in the first trimester by measles, chickenpox, mumps, poliomyelitis, or influenza.

The studies of rubella and congenital malformations suggest that CP occasionally may be associated with viral infections. Little is known about the frequency of the rubella-malformation association, nor is it known whether other viral agents may produce the same or other congenital lesions ( 77 ).

The relation of toxoplasmosis to the prevalence of clefts has been investigated by the use of skin tests and the Sabin-Feldman dye test (SFT) on the mothers of normal and affected children (78). Sixty-one mothers of children with clefts were tested with the SFT. Four, or 6.6 percent, were positive, compared with 3 percent of the control group which consisted of 100 women of the same age as the study group. A toxoplasmosis skin test was strongly positive in 66.5 percent of 66 children with clefts and in 11 percent of the controls. With the small number of study cases and the questionable specificity of the SFT and skin test for toxoplasmosis, it seems that no definite conclusions can be drawn from this study. Further epi- 
demiologic investigations to determine why the apparent association exists seem indicated.

To explain an urban-rural difference in incidence of clefts, Pleydell (79) suggested that the higher population density in urban areas might result in more infections during the prenatal period. He reported a 1.3 to 1 ratio of cleft incidence in urban versus rural areas of England.

Radiation. Laboratory studies have demonstrated that CP can be produced in the offspring of rats by exposing pregnant rats to roentgen rays (80). Murphy (81) found no clefts in his study of 24 children of mothers who had received therapeutic pelvic irradiation sometime during the first 5 months of pregnancy. The series was very small and it is not known how many of these mothers received therapy during the 6th to 12th week of their pregnancies.

No clefts were reported among children exposed in utero during the atomic bombing of Hiroshima (82). Children of 11 mothers who were less than 16 weeks pregnant and within 1,200 meters of the Hiroshima hypocenter at the time of detonation were examined.

In a study of congenital malformations in relation to geological formations in New York State, Gentry (8) reported more cleft cases in "probable" areas (1.6 per 1,000) than in "unlikely" areas (1.2 per 1,000). The "probable" areas were those having a certain type of geological formation which supposedly contains radioactive elements. No measurement was made of the radiation the mothers received, and only fragmentary details were given of the methods used for arriving at the case rates. The data therefore can be considered no more than suggestive. If the greater incidence of clefts in the "probable" areas resulted from radiation, it would be interesting to know whether a particular type of cleft accounted for the increase.

No human epidemiologic studies of the relation between diagnostic $\mathrm{X}$-rays and congenital clefts were found in the literature.

\section{SUMMARY AND OBSERVATIONS}

Out of a potpourri of theory, belief, and fact, the descriptive epidemiology of cleft lip and palate is emerging. At this time, however, the epidemiologic picture is still somewhat muddled and confused. The literature contains conflicting reports of wide variations in incidence by geographic location, sex, parental age, race, and season of birth. The data on which many of these reports rest their cases are less than adequate.

Though there is strong evidence that both genetic and environmental forces are involved in cleft formation, the genetic mechanism has not been described adequately nor have specific environmental agents been identified. Theories based on environment alone or on genetics alone cannot fully explain the data in the literature.

The epidemiologist who would attempt to investigate cleft lip and palate should be intrigued and challenged by the perplexing questions with which he is faced. Are some cases of cleft lip and palate purely genetically determined and others purely environmentally determined? Are there inherited modifiers of genetic and extragenetic teratogenic forces? Are there environmental modifiers of genetic forces? That these questions remain unanswerable today may indicate that facial clefts result from a complex interplay of an unknown number of genetic and extragenetic forces. The fact that investigators are now able to raise more intelligent questions about the roles of heredity and environment in cleft formation attests to the progress that has been made toward understanding the mechanisms involved, but it also indicates that the surface has hardly been scratched.

\section{REFERENCES}

(1) Stevenson, S., Worcester, J., and Rice, R. G.: 677 congenitally malformed infants and associated gestational characteristics. I. General considerations. Pediatrics 6 : 37-50, July 1950.

(2) Warkany, J., and Nelson, R. C.: Appearance of skeletal abnormalities in the offspring of rats reared on deficient diets. Science 92 : 383-384, Oct. 25, 1940.

(\$) Canick, M. L. : Cleft lip and cleft palate-a review of embryology, pathologic anatomy, and etiology. Plast Reconstr Surg 14: 30-46, July 1954.

(4) Cannon, B., Fisher, D., and Britton, H. C. : Plastic surgery: harelip and cleft palate. New Eng J Med 245 : 179-185, Aug. 2, 1951.

(5) Stark, R. B.: The pathogenesis of harelip and cleft palate. Plast Reconstr Surg 13: 20-39, January 1954. 
(6) Hixon, E. H. : A study of the incidence of cleft lip and cleft palate in Ontario. Canad J Public Health 42: 508-511, December 1951.

(y) Krantz, H. C., and Henderson, F. M.: Relationship between maternal ancestry and incidence of cleft palate. $J$ Speech Hearing Dis 12: 267-278, September 1947.

(8) Gentry, J. T., Parkhurst, E., and Bulin, G. V., Jr.: An epidemiological study of congenital malformations in New York State. Amer J Public Health 49: 497-513, April 1959.

(9) MacMahon, B., and McKeown, T.: The incidence of harelip and cleft palate related to birth rank and maternal age. Amer J Hum Genet 5 : 176183, June 1953.

(10) Ivy, R. H.: Congenital anomalies as recorded on birth certificates. Plast Reconstr Surg 20: 400-411, November 1957.

(11) Loretz, W., Westmoreland, W. W., and Richards, L. F.: A study of cleft lip and cleft palate births in California, 1955. Amer $\mathrm{J}$ Public Health 51 : 873-877, June 1961.

(12) Fogh-Andersen, P.: Incidence of cleft lip and palate: constant or increasing? Acta Chir Scand 122: 106-111, September 1961.

(13) U.S. Bureau of the Census : Statistical abstract of the United States, 1960. U.S. Government Printing Office, Washington, D.C., 1960.

(14) U.S. Bureau of the Census : Census of population: 1960. Advance reports, final population counts, PC(A1)-1. Washington, D.C., Nov. 15, 1960.

(15) Fogh-Andersen, P.: Inheritance of harelip and cleft palate. A. Busck, Copenhagen, 1942, chs. 6, 9-13.

(16) Ivy, R. H. : Address before American Academy for Cleft Palate Rehabilitation, ninth annual meeting, Philadelphia, April 17, 1951. As cited in reference 6 .

(17) Mazaheri, M.: Statistical analysis of patients with congenital cleft lip and/or palate at the Lancaster cleft palate clinic. Plast Reconstr Surg 21 : 193-203, March 1958.

(18) Fraser, F. C., and Baxter, H.: The familial distribution of congenital clefts of the lip and palate. Amer J Surg 87 : 656-659, May 1954.

(19) Fraser, G. R., and Calnan, J. S.: Cleft lip and palate: seasonal incidence, birth weight, birth rank, sex, site, associated malformations and parental age; a statistical survey. Arch Dis Child 36 : 420-423, August 1961.

(20) Phair, G. M.: The Wisconsin cleft palate program. J Speech Hearing Dis $12: 410-414$, December 1947.

(21) Davis, W. B.: Harelip and cleft palate. Ann Surg 87 : 536-554, April 1928.

(22) Ritchie, H. P.: Congenital clefts of the face and jaws; a survey of 350 cases in which operation was performed. Arch Surg 28: 617-658, April 1934.

(23) McEvitt, W. G.: Cleft lip and palate and parental age. Plast Reconstr Surg 10: 77-82, August 1952.

(24) Peer, L. A., et al.: Study of 400 pregnancies with birth of cleft lip-palate infants. Plast Reconstr Surg 22 : 442-449, November 1958.

(25) Beder, O. E., Coe, H. E., Braafladt, R. P., and Houle, J. D.: Factors associated with congenital cleft lip and cleft palate in the Pacific Northwest. Oral Surg $9:$ 1267-1273, December 1956.

(26) Davis, J. S. : The incidence of congenital clefts of the lip and palate. Ann Surg 80: 363-374, September 1924.

(27) Lutz, K. R., and Moor, F. B.: A study of factors in the occurrence of cleft palate. $J$ Speech Hearing Dis 20 : 271-276, September 1955.

(28) Grace, L. G.: Frequency of occurrence of cleft palates and harelips. J Dent Res $22: 495-497$, December 1943.

(29) U.S. Army, Office of the Surgeon General : Defects found in drafted men. U.S. Department of War, Washington, D.C., 1920. As cited in T. W. Brophy: Cleft lip and palate. Blakiston, Philadelnhia, 1923, pp. 301-302.

(30) Henderson, F. M.: Incidence of cleft palate in Hawaii. J Speech Hearing Dis 5: 285-287, September 1940.

(31) Stiegler, E. J., and Berry, M. F.: A new look at the etiology of cleft palate. Plast Reconstr Surg 21 : 52-73, January 1958.

(32) Schwartz, R. : Familial incidence of cleft palate. J Speech Hearing Dis 19 : 228-238, June 1954.

(33) Davis, W. B. : Congenital deformities of the face. Surg Gynec Obstet 61: 201-209, August 1935.

(34) Metrakos, J. D., Metrakos, K., and Baxter, H.: Clefts of the lip and palate in twins. Plast Reconstr Surg 22 : 109-122, August 1958.

(35) Douglas, B.: Deductions from the presence of cleft lip and palate in one of identical twins, from embryology and from animal experiments. Plast Reconstr Surg 22: 94-108, August 1958.

(36) Curtis, E.: Genetical and environmental factors in the etiology of cleft lip and cleft palate. J Canad Dent Assoc 23 : 576-580, October 1957.

(37) Rank, B. K., and Thomson, J. A.: Cleft lip and palate in Tasmania. Med J Aust $47: 681-689$, October 1960.

(38) Warkany, J.: Etiology of congenital malformations. Advances Pediat 2 : 1-63, 1947.

(39) Mather, K., and Philip, U.: Inheritance of harelip and cleft palate in man. Ann Eugenics 10 : 403-416, December 1940.

(40) Warkany, J.: Congenital malformations induced by maternal nutritional deficiency. $J$ Pediat 25 : 476-480, December 1944.

(41) Warkany, J.: Congenital anomalies. J Pediat $7:$ : 607-610, May 1951.

(42) Warkany, J., and Schraffenberger, E.: Congenital malformations induced in rats by maternal nutritional deficiency; the preventive factor. J Nutr 27 : 477-484, June 10, 1944. 
(43) Warkany, J., Nelson, R. C., and Schraffenberger, E. : Congenital malformations induced in rats by maternal nutritional deficiency. IV. Cleft palate. Amer J Dis Child 65: 882-894, June 1943.

(44) Hale, F.: The relation of vitamin A to anophthalmos in pigs. Amer J Ophthal 18: 10871093, December 1935.

(45) Cohlan, S. Q.: Excessive intake of vitamin A as a cause of congenital anomalies in the rat. Science 117 : 535-536, May 15, 1953.

(46) Evans, H. M., Nelson, M. M., and Asling, C. W. : Multiple congenital abnormalities resulting from acute folic acid deficiency during gestation. Science 114: 479, Nov. 9, 1951.

(47) Nelson, M. M., Wright, H. V., Baird, C. D. C., and Evans, H. M.: Teratogenic effects of pantothenic acid deficiency in the rat. J Nutr 62 : 395-405, July 1957.

(48) Cheng, D. W., Chang, L. F., and Bairnson, T. A. : Gross observations on developing abnormal embryos induced by maternal vitamin $\mathbf{E}$ deficiency. Anat Rec 129: 167-185, October 1957.

(49) Murphy, M. L., Dagg, C. P., and Karnofsky, D. A. : Comparison of teratogenic chemicals in the rat and chick embryos; an exhibit with additions for publication. Pediatrics 19: 701714, April 1957.

(50) Douglas, B.: Role of environmental factors in the etiology of "so-called" congenital malformations. II. Approaches in humans; study of various extragenital factors; "theory of compensatory nutrients," development of regime for first trimester. Plast Reconstr Surg 22 : 214-229, September 1958.

(51) McGanity, W. J., et al. : Effect of severe maternal dietary deficiency in causing infant deformity. Amer J Obstet Gynec 67 : 491-527, March 1954.

(52) Conway, H.: Effect of supplemental vitamin therapy on the limitation of incidence of cleft lip and cleft palate in humans. Plast Reconstr Surg 22: 450-453, November 1958.

(53) Langman, J. : The influence of teratogenic agents on serum proteins. In Congenital anomalies of the face and associated structures. Proceedings of an international symposium. Charles C Thomas, Springfield, 1961, pp. 149-161.

(54) Fainstat, T. D.: Cortisone-induced congenital cleft palate in rabbits. Endocrinology 55: 502-508, October 1954.

(55) Fraser, F. C., Kalter, H., Walker, B. E., and Fainstat, T. D.: The experimental production of cleft palate with cortisone and other hormones. J Cell Comp Physiol (supp. 1) 43 : 237-259, May 1954.

(56) Fraser, F. C., and Fainstat, T. D.: Causes of congenital defects; a review. Amer $J$ Dis Child 82 : 593-603, November 1951.

(57) Doig, R. K., and Coltman, O. M. : Cleft palate following cortisone therapy in early pregnancy. Lancet 2: 730, October 6, 1956.
(58) Harris, J. W. S., and Ross, I. P. : Cortisone therapy in early pregnancy : relation to cleft palate. Lancet 1 : 1045-1047, June 30, 1956.

(59) DeCosta, E. J., and Abelman, M. A. : Cortisone and pregnancy. Amer $J$ Obstet Gynec 64: 746-767, October 1952.

(60) Strean, L. P., and Peer, L. A. : Stress as an etiologic factor in the development of cleft palate. Plast Reconstr Surg 18: 1-8, July 1956.

(61) Gregg, N. M. : Congenital cataract following German measles in the mother. Trans Ophthal Soc Aust 3 : 35-46 (1941).

(62) Prendergast, J. J.: Congenital cataract and other anomalies following rubella in mothers during pregnancy. Arch Ophthal 35:39-41, January 1946.

(63) Ober, R. E., Horton, R. J. M., and Feemster, R. F. : Congenital defects in a year of epidemic rubella. Amer J Public Health 37 : 1328-1333, October 1947.

(64) Greenberg, M., Pellitteri, O., and Barton, J.: Frequency of defects in infants where mothers had rubella during pregnancy. JAMA 165: 675-678, October 12, 1957.

(65) Swan, C. : Rubella in pregnancy as an aetiological factor in congenital malformations, stillbirth, miscarriage and abortion. Part 1 . J Obstet Gynaec Brit Emp 56: 341-363, June 1949.

(66) Swan, C. : Rubella in pregnancy as an aetiological factor in congenital malformations, stillbirth, miscarriage and abortion. Part 2. J Obstet Gynaec Brit Emp 56: 591-605, August 1949.

(67) Swan, C., and Tostevin, A. L.: Congenital abnormalities in infants following infectious diseases during pregnancy with special reference to rubella : a third series of cases. Med J Aust 1 : 645-659, May 11, 1946.

(68) Swan, C., Tostevin, A. L., and Black, G. H. B. : Final observations on congenital defects in infants following infectious diseases during pregnancy, with special reference to rubella. Med J Aust 2: 889-908, December 28, 1946.

(69) Conte, W. R., McCammon, C. S., and Christie, A. : Congenital defects following rubella. Amer J Dis Child 70: 301-306, November-December 1945.

(70) Albaugh, C. H.: Congenital anomalies following maternal rubella in early weeks of pregnancy. JAMA 129: 719-723, November 10, 1945.

(71) Fox, M. J., and Bortin, M. M.: Rubella in pregnancy causing malformations in newborm. JAMA 130 : 568-569, Mar. 2, 1946.

(72) Dogramaci, I., and Green, H.: Factors in the etiology of congenital heart anomalies. $J$ Pediat 30 : 295-301, March 1947.

(73) Aycock, W. L., and Ingalls, T. H.: Maternal disease as a principle in the epidemiology of congenital anomalies, with a review of rubella. Amer J Med Sci 212: 366-379, September 1946.

(74) Patrick, P. R.: Report of a survey of children born in 1941 with reference to congenital ab- 
normalities arising from maternal rubella. Med J Aust 1 : 421-425, Apr. 3, 1948.

(75) Brawner, D. L.: Maternal rubella: results following an epidemic. J Med Assoc Georgia 44: 451-454, September 1955.

(76) Ministry of Health, Great Britain: Rubella and other virus infections during pregnancy. Reports on public health and medical subjects. No. 101. Her Majesty's Stationery Office, London, 1960.

(yy) Melnick, J. L., and Sabin, A. B. : The ECHO virus group. In Viral and rickettsial infections of man, edited by T. M. Rivers and F. L. Horsfall. Ed. 3. J. P. Lippincott Co., Philadelphia, 1959, pp. 547-569.

(78) Erdelyi, R.: The influence of toxoplasmosis on the incidence of congenital facial malformations ; preliminary report. Plast Reconstr Surg 20 : 306-310, October 1957.

(79) Pleydell, M. J.: Anencephaly and other congenital abnormalities; an epidemiological study in Northhamptonshire. Brit Med J No. 5169: 309-315, Jan. 30, 1960.

(80) Warkany, J., and Schraffenberger, E. : Congenital malformations induced in rats by roentgen rays. Amer J Roentgen 57 : 455-463, Apr 1947.

(81) Murphy, D. P.: Congenital malformations. Ed. 2. J. P. Lippincott Co., Philadelphia, 1947, pp. 87-100.

(82) Plummer, G.: Anomalies occurring in children exposed in utero to the atomic bomb in Hiroshima. Pediatrics 10:687-693, December 1952.

\section{Aphthous Stomatitis}

A virus-like variant of a bacterium may be a mechanism of recurrence of aphthous stomatitis, or canker sores, reported Dr. E. A. Graykowski and Dr. M. F. Barile of the National Institutes of Health at a meeting of the International Association for Dental Research.

The organism was isolated from oral aphthous lesions of five patients. From recurring lesions in one of the patients the organism was isolated in pure culture during six exacerbations over a 7-month period. The organism was isolated from the patient's blood during three acute phases of the infection and was absent from the blood during the quiescent periods.

The organism was recovered also during remission of the infection from tissue at the site of previous lesions. This finding, the investigators feel, suggests that a phase of the organism can remain dormant and may be responsible for the recurrence of lesions at the same site.

The organism is a transitional L-form of a bacterium. The L-form is similar to the pleuropneumonia-like group of organisms which was recently shown to cause some cases of atypical pneumonia in man. The L-form may exist independently or with its bacterial parent, and the two vastly different phases can alternate in a cyclic manner through many intermediate stages.

The scientists indicated that findings so far suggest that a relationship exists between the $\mathrm{L}$-forms and the pathogenesis of aphthous stomatitis and that at least some cases of the disease are infectious. 